\title{
Investigation of Serum Levels of Leptin, Ghrelin and Growth Hormone in Bahraini Children with Autism
}

\author{
Zuheir Ahmed Hasan, PhD', Ghada Al-Kafaji, PhD',*, Maryam Isa Al-Sherawi, PhD', Rima Abdul \\ Razzak, PhD', Diab Eltayeb, PhD ${ }^{4}$, Cristina Skrypnk, MD, PhD and Moiz Bakhiet, MD, PhD
}

\begin{abstract}
${ }^{1}$ Department of Physiology, College of Medicine and Medical Sciences, Arabian Gulf University, Kingdom of Bahrain

${ }^{2}$ Department of Molecular Medicine and Al-Jawhara Centre for Molecular Medicine, Genetics and Inherited Disorders, College of Medicine and Medical Sciences, Arabian Gulf University, Kingdom of Bahrain

${ }^{3}$ Department of Intellectual Disability and Autistic Disorder, College of Graduate Studies, Arabian Gulf University, Kingdom of Bahrain
\end{abstract}

${ }^{4}$ Al-Jawhara Centre for Molecular Medicine, Genetics and Inherited Disorders, College of Medicine and Medical Sciences, Arabian Gulf University, Kingdom of Bahrain

*Corresponding author: Ghada Al-Kafaji, Department of Molecular Medicine, College of Medicine and Medical Sciences, Arabian Gulf University, Salmaniya Avenue, Building 293, Road 2904, Block 329, Manama, Kingdom of Bahrain, Tel: +97317239305, Fax: $+973-17246022$

\begin{abstract}
Autism is a complex neurodevelopmental disorder, the pathogenesis of which remains unclear. Recent research suggests a possible role of hormonal abnormalities in the pathogenicity of autism. In this investigation, we measured serum levels of leptin, ghrelin, and growth hormone $(\mathrm{GH})$ in 40 age-matched Bahraini children, 20 with autism ( 16 males and 4 females) and 20 healthy children ( 13 males and 7 females). Hormonal levels were measured by enzyme-linked immunosorbent assay method.

Leptin levels were found to be significantly higher in children with autism $(78.05 \pm 17.99)$ than in healthy control children (19.96 \pm 11.20$)$, $(P=0.038)$. Conversely, ghrelin levels were lower in children with autism (62.40 \pm 16.98$)$ than in controls $(91.50 \pm 36.30)$, however, without reaching statistical significance $(P=0.32)$. Similarly, $G H$ levels were lower in children with autism $(0.63 \pm 0.02)$ than in controls $(0.72 \pm 0.09)$, but didn't reach statistical significance $(P=$ 0.33). Regression analysis confirmed a direct association between higher leptin levels and autism (OR: 0.896, 95\% Cl: $0.816-0.984, P=0.021)$, and this association remained significant after adjustment for age, sex and body mass index (OR: $0.800,95 \% \mathrm{Cl}$ : 0.669-0.956, $\mathrm{P}=0.014$ ).
\end{abstract}

The significantly higher levels of leptin in autistic children may suggest an important role of this hormone in the pathophysiology of autism. While the levels of ghrelin and $\mathrm{GH}$ seemed to be low in autistic children, both were not significantly different than in controls. This study is particularly important to improve translation from medical research to health policy in Bahrain, and further validation studies with a larger sample size are required to clarify the relation of these hormones with autism.

Keywords

Autism, Leptin, Ghrelin, Growth hormone

\section{Introduction}

Autism is a neurological and developmental condition characterized by impaired social interaction, deficit in language and the presence of stereotypic and obsessive behaviours [1]. Additional features may include poor eye contact, sensory modulatory dysfunction $[2,3]$, and variable levels of cognition and motor disturbances [4,5]. The condition is known as an autism spectrum disorder (ASD) because of the wide variation in the type and severity of symptoms. Autism has be-

Citation: Hasan ZA, Al-Kafaji G, Al-Sherawi MI, Razzak RA, Eltayeb D, et al. (2019) Investigation of Serum Levels of Leptin, Ghrelin and Growth Hormone in Bahraini Children with Autism. Int Arch Transl Med 5:007. doi.org/10.23937/2572-4142.1510007

Accepted: March 09, 2019: Published: March 11, 2019

Copyright: (c) 2019 Hasan ZA, et al. This is an open-access article distributed under the terms of the Creative Commons Attribution License, which permits unrestricted use, distribution, and reproduction in any medium, provided the original author and source are credited. 
come a substantial health burden and the prevalence of the disorder has rapidly increased in the developed countries [6,7], and in the Arab Gulf countries [8]. Autism affects males more often than females, yet, no exact mechanism has yet to definitively account for this sex difference [9].

The etiology of autism is not well understood. However, genetic and epigenetic changes [10,11], as well as environmental factors and immune dysfunction have been reported to be implicated in autism [12-14]. Moreover, alterations in the levels of neurotransmitters such as dopamine metabolism [15], and dysregulations of serotonergic systems $[16,17]$ have been suggested to play a role in the pathogenesis of autism. Imbalance in the immune and inflammatory processes in autism, and an association between allergy, hypersensitivity and asthma with ASD have been described in recent studies [18-20]. The studies have also shown that children with ASD are at risk of having gastrointestinal (GI) tract conditions including constipation, diarrhea, and abdominal pain [21], and the frequent GI problems that affect ASD children are more common than in children with typical development [22].

Recently, a wide range of hormones and neuropetides have been investigated in autism [23]. Among them, leptin has been suggested to play a role in autism [24]. Leptin is a peptide hormone, mainly secreted by adipose tissues and acts as a mediator of long-term regulation of body weight and energy expenditure at the hypothalamic level [25]. Leptin also has a robust role in the brain and its receptors are highly expressed and in several regions of the human brain, including the cortex, amygdala, hippocampus, and thalamus [26,27]. In addition, leptin plays an important role in the regulation of the neuroendocrine system, reproductive system, immune system, bone development, and brain development [27].

Ghrelin is another peptide hormone which has been shown to be altered in autism [28]. Ghrelin is produced mainly in gastrointestinal tissues [29], and exerts multiple physiological functions including the modulation of energy metabolism and regulation of autonomic functions. It also plays a significant role in synaptogenesis, mainly in the hippocampal area [30], and abnormal synaptic homeostasis in this area has been reported as a risk factor for autism [31]. In the central nervous system (CNS), ghrelin has a proliferative anti-apoptotic effect especially during oxygen/glucose deprivation, thus, it may protect the hypothalamus against reactive oxygen species (ROS), which have been linked to autism [32]. Recent studies have revealed that the levels of ghrelin could be changed in epilepsy [33], a condition which is more common in people with autism [34].

While both hormones have a major influence on energy balance, the action of ghrelin is opposed by the action of leptin [29]. Moreover, a potential link between leptin and ghrelin has been reported, wherein gastric leptin inhibits ghrelin mRNA expression and reduces its level in a dose-dependent manner [35]. Both leptin and ghrelin are also linked to allergy. In human and murine studies, the pro-inflammatory effects of the two hormones leptin and ghrelin have been shown to be relevant to asthma [36,37]. The two hormones have some immunomodulatory effects and counteract each other with regard to the production of pro-inflammatory cytokines TNF- $\alpha$ and IL-1 $\beta$ on human lymphocytes in vitro [38].

There is also a connection between leptin, ghrelin and growth hormone $(\mathrm{GH})$. Leptin stimulates $\mathrm{GH}$ secretion by acting directly on the hypothalamic-pituitary axis [39], whereas ghrelin stimulates the release of $\mathrm{GH}$ through the expression of the $\mathrm{GH}$ secretagogue receptor type 1a (GHS-R1a) in the hypothalamus and pituitary [40]. GHS-R1a is also expressed in other brain regions, including the hippocampus. This limbic structure which plays an important role in memory, is a primary target for ghrelin action and is modulated in autism [41].

To gain further insight into the role of these hormones in autism, the current study aimed to investigate the levels of leptin, ghrelin and $\mathrm{GH}$ in Bahraini children with autism and age-matched healthy controls. This study may provide an additional evidence for the implication of these hormones in the pathogenicity of autism, and could be particularly important in translation medicine to improve population health.

\section{Methods}

\section{Participants}

In this case-control study, a total of 20 children with autism and 20 age-matched healthy control children were enrolled. Children with autism were recruited from AlWafa centre, a sub-division of Bahrain Association of Intellectual Disability and Autism, and from Aalia Early Intervention Centre in Bahrain. The autistic children met the criteria for Autistic Disorder [42]. According to the Childhood Autism Rating Scale (CARS) [43], the autistic children included in this study had no intellectual disability. They also had no neurological diseases or metabolic disorders. The healthy control children were recruited by advertisement. Their medical history confirmed the absence of any endocrine abnormalities, neurological disorders or other medical conditions. Information including age, gender, weight and height were collected from all participants. The body mass index (BMI) was calculated as weight in kilograms (Kg) divided by the square of height in meters $(\mathrm{m})^{2}$.

\section{Ethics approval}

Ethical approval to conduct the current study was obtained from the directorate council of both AIWafa Centre and Aalia Early Intervention Centre in Bahrain 
Table 1: Characteristics of study subjects.

\begin{tabular}{|l|l|l|l|}
\hline Parameters & Autism & Healthy & P-value \\
\hline Number $(\mathrm{n})$ & 20 & 20 & \\
\hline Age $($ years) & $5.9 \pm 2.15$ & $6.0 \pm 2.17$ & NS \\
\hline Male $[\mathrm{n}(\%)]$ & $16(80)$ & $13(65)$ & NS \\
\hline Female $[\mathrm{n}(\%)]$ & $4(20)$ & $7(35)$ & NS \\
\hline Weight $(\mathrm{kg})$ & $21.26 \pm 4.94$ & $31.17 \pm 11.13$ & $<0.001$ \\
\hline Height $\left(\mathrm{m}^{2}\right)$ & $1.17 \pm 0.08$ & $1.32 \pm 0.14$ & $<0.001$ \\
\hline BMl $\left(\mathrm{kg} / \mathrm{m}^{2}\right)$ & $15.5 \pm 2.60$ & $17.6 \pm 4.15$ & $<0.05$ \\
\hline
\end{tabular}

BMI: Body Mass Index; NS: Non-Significant.

Data are presented as numbers $(\%)$ for categorical data or mean \pm standard deviation (SD) for parametrically distributed data.

as well as from the Medical Research and Ethics Committee in the College of Medicine and Medical Sciences, Arabian Gulf University, Bahrain. The parents and guardians of all participants were given a complete description of the study, and provided written informed consent according to the guidelines of the College of Medicine and Medical Sciences, Arabian Gulf University.

\section{Blood sampling hormonal measurements}

Blood samples $(5 \mathrm{ml}$ ) from participants were directly collected into serum Vacutainer tubes (BD) after an overnight fasting. The tubes were allowed to clot for 30-60 min at room temperature, and then serum was obtained by centrifugation at 2,000 $\times \mathrm{g}$ for $5 \mathrm{~min}$.

The studies have shown that peptide hormones, cytokines and inflammatory markers are relatively stable when stored under cooled conditions [39,44]. In the current study, the collected serum were used immediately or frozen immediately at $-80{ }^{\circ} \mathrm{C}$ and used within three days after blood collection. Serum levels of leptin, ghrelin, and growth hormone $(\mathrm{GH})$ were measured using the commercially available enzymelinked immunosorbent assay (ELISA) kits (Sigma Aldrich, UK or Abcam, USA) according to the manufacturer instructions.

\section{Statistical analysis}

The SPSS software (version 23; IBM Corp., Armonk, NY, USA) was used to analyze the data. Comparisons of serum levels leptin, ghrelin and $\mathrm{GH}$, as well as other parameters between autism children and healthy controls were conducted by Student's unpaired t-test, and presented as the mean \pm standard deviation (SD). Multivariate regression analysis regression was used to test the relationships between the levels of hormones and autism. The odds ratios (ORs) and 95\% confidence intervals (Cls) were calculated with multi-adjustment for several variables. All tests were two-tailed and statistical significance was accepted at $P<0.05$.

\section{Results}

\section{Characteristics of study subjects}

The study included 20 children with autism and 20 age-matched healthy children. The characteristics of the study participants are shown in Table 1 . The age of participants ranged between 4 to 12 years in the group of children with autism and ranged between 4 to 11 years in the group of healthy control children. In the autism group, there were 16 males and 4 females. In the control group, there were 13 males and 7 females. The weight and height differed significantly between the autism group and the control group $(P<0.001)$. The body mass index (BMI) was significantly lower in the autism group compared with the control group ( $P$ $<0.005)$. The mean of BMI for children with autism was $15.5 \pm 2.60 \mathrm{~kg} / \mathrm{m}^{2}$ and for the healthy children was 17.6 $\pm 4.15 \mathrm{~kg} / \mathrm{m}^{2}$, which indicates no obesity in both groups.

\section{Serum levels of leptin, ghrelin, and growth hormone}

The levels of leptin, ghrelin, and growth hormone $(\mathrm{GH})$ in serum were measured by enzyme-linked immunosorbent assay (ELISA) method in children with autism and age-matched healthy control children.

As shown in Figure $1 \mathrm{~A}$, serum levels of leptin were significantly higher in children with autism than in healthy control children $(P=0.038)$. The mean of serum leptin for the autism group was $78.05 \mathrm{pg} / \mathrm{mL} \pm 17.99$ and for the healthy group was $19.96 \mathrm{pg} / \mathrm{mL} \pm 11.20$.

On the other hand, serum levels of ghrelin were lower in children with autism than in healthy control children (Figure 1B), although without reaching statistical significance $(P=0.32)$. The mean of serum ghrelin for the autism group was $62.40 \mathrm{ng} / \mathrm{mL} \pm 16.98$ and for the healthy group was $91.50 \mathrm{ng} / \mathrm{mL} \pm 36.30$.

Likewise, serum levels of $\mathrm{GH}$ were lower in children with autism than in healthy control children (Figure 1C), but didn't reach statistical significance $(P=0.33)$. The mean of serum $\mathrm{GH}$ for the autism group was $0.63 \mathrm{ng} / \mathrm{mL}$ \pm 0.02 and for the healthy group was $0.72 \mathrm{ng} / \mathrm{mL} \pm 0.09$.

\section{Regression analysis}

As we have found significantly higher levels of serum leptin in children with autism compared with the healthy children, we further evaluated the relationship between leptin and autism by multivariate regression analysis. 

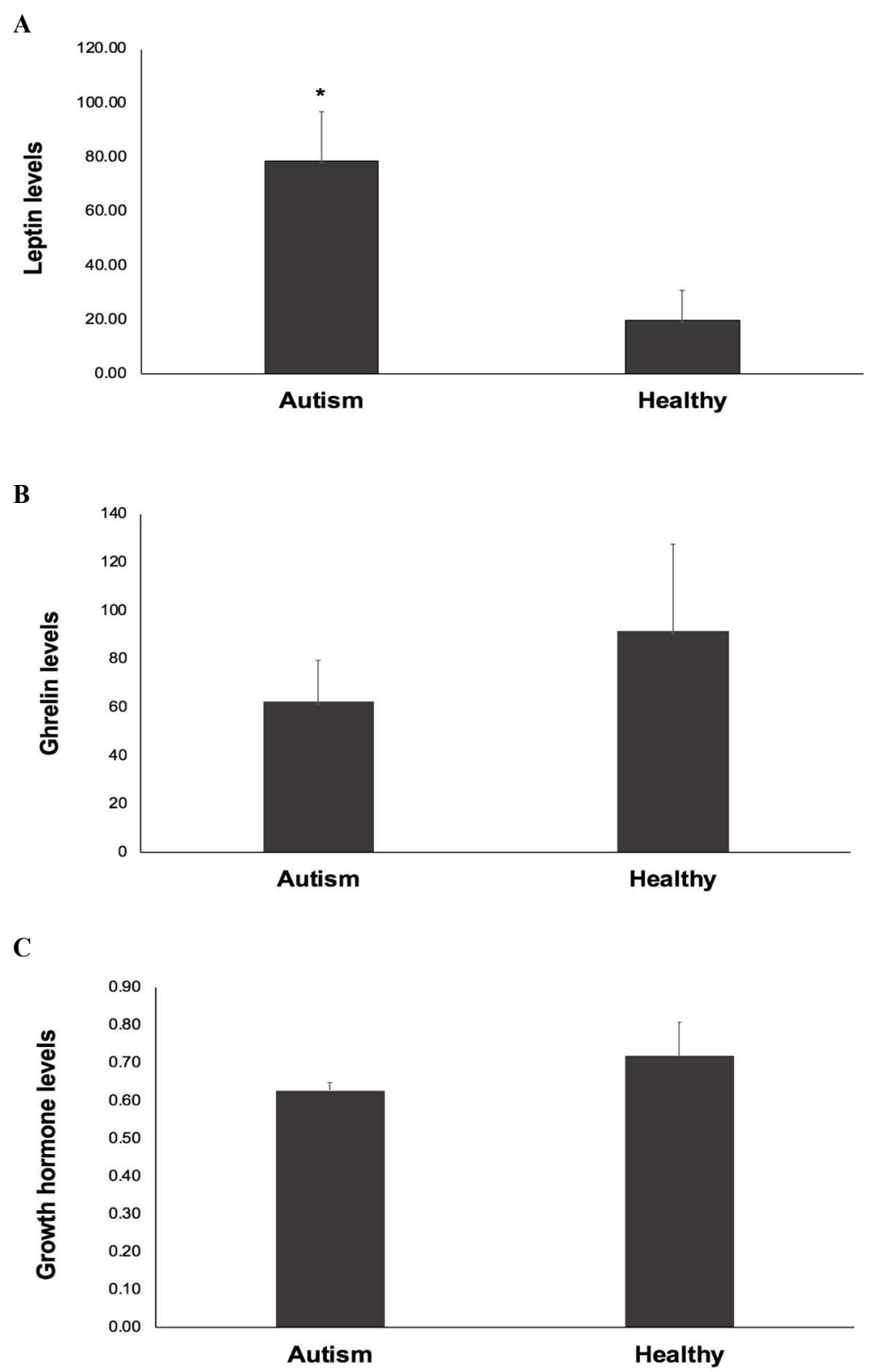

Figure 1: Serum levels of leptin, ghrelin, and growth hormone in autistic children and healthy controls. The levels of leptin, ghrelin, and growth hormone $(\mathrm{GH})$ in serum were measured by enzyme-linked immunosorbent assay (ELISA) method in children with autism and age-matched healthy control children. Figure 1A: Leptin levels; Figure 1B: Ghrelin levels; Figure 1C: Growth hormone levels. Data are presented as the mean \pm deviation (SD). ${ }^{*} \mathrm{P}<0.05$ vs. healthy controls.

Table 2: Multivariate regression analysis: Association between leptin levels and autism.

\begin{tabular}{|l|l|l|l|}
\hline Models & OR & $95 \%$ Cl & P-value \\
\hline Model 1 & 1.06 & $1.020-1.120$ & 0.034 \\
\hline Model 2 & 1.07 & $1.025-1.134$ & 0.026 \\
\hline
\end{tabular}

OR: Odds Ratio; Cl: Confidence Interval.

Model 1 unadjusted, model 2 adjusted for age, sex and body mass index (BMI).

Using the healthy control group as the reference category, the results (Table 2 ) revealed a direct and independent association between higher leptin levels and autism incidence (odds ratio [OR]: 0.896, 95\% confidence interval $[\mathrm{CI}]: 0.816-0.984, \mathrm{P}=0.021)$. These results also adjusted for age, sex and BMI and continued to show a significant association between leptin and autism (OR: $0.800,95 \% \mathrm{Cl}: 0.669-0.956, \mathrm{P}=0.014)$.

\section{Discussion}

Autism is a heterogeneous group of neurodevelopmental disorder characterized by impaired social interaction and communication, preference for repetitive, stereotyped behaviours [1], sensory modulatory dysfunction $[2,3]$ and cognition and motor disturbances $[4,5]$. Although the cause of autism remains unclear, various factors or combination of factors are believed to contribute its etiology [10-14]. Recent studies have shown that abnormalities in various neurotransmitters [15-17], and alterations in the levels of hormones and neuropetides [23] are implicated in the pathogenicity of autism.

In the current study, we investigated serum levels 
of leptin, ghrelin, and growth hormone (GH) in children with autism and age-matched healthy control children to gain an insight into the implication of these hormones in autism.

We found that leptin levels were significantly higher in children with autism than in healthy children. In multivariate logistic regression analysis, a significant association between leptin and autism incidence was observed, even after adjustment for age, sex and BMI, suggesting a direct link between increased leptin levels and autism. The finding in this study of significant higher leptin levels in the autistic children than in the healthy children is consistent with previous reports $[24,28]$. Leptin is an important peptide hormone mainly secreted by adipose tissues, and is involved in regulating various processes including dietary intake, body weight and energy balance at the hypothalamic level [25]. It increases energy expenditure and thermogenesis by stimulating the sympathetic nervous system [45]. Leptin is also a cytokine-like hormone with pleiotropic actions and plays a significant role in the immune system, inflammatory response and neuroendocrine functions $[46,47]$. It is among the neuroendocrine mediators that have an effect on the immune system, and a change in the immune response may impact several biological systems including the neuroendocrine and nervous systems. There is mounting evidence of neurological, immunological, and autonomic abnormalities in children with ASD $[13,14]$ and alterations in the immunoinflammatory system and increases in pro-inflammatory cytokines have been described in both children and adults with ASD [14]. Although the exact mechanism of leptin in autism remains unclear, increased leptin levels in autistic children observed in the current study may suggest a role for this hormone in the pathogenesis of the disease. This suggestion is supported by previous investigations showed an association between higher leptin levels in autism and early onset phenotype [24], and the clinical manifestations of the disease [48]. Given the cytokine-like function of leptin in the immune system $[46,47]$ its elevation in children with autism may suggest a participation of this hormone in the immune response to inflammation. Previous studies have shown an association between the levels of leptin and ghrelin with adiposity $[25,49,50]$. In our study, high leptin levels and low ghrelin levels were found in children with autism who had no indication of obesity. As can be seen from the anthropometric data in the current study (Table 1), there was a significant difference in body weight between the autism and control groups, which was significantly lower in the autism group. The observation that the autistic children had decreased weight despite high leptin (an anorexigenic hormone) levels and low ghrelin (an orexigenic hormone) may suggest an impairment in the central processing of such peripheral signals. Moreover, many other hormones rather than leptin may play roles in body weight. In addition, this observation may also emphasize more on the pro-neuroimmune inflammatory cytokine effect of leptin in the complex neurometabolic mechanisms involved in autism $[24,51]$, rather than only a neuroendocrine mediator for regulation of energy intake and expenditure by a negative feedback. However, other biochemical and metabolic measures are required to rule out leptin resistance.

One recent study by Al-Zaid, et al. [28] has shown a significant reduction in the levels of ghrelin and GH in boys diagnosed with autism. However, their study lacks female subjects with autism, whereas in the current study we included both males and females with autism, but we found no significant decreases in the levels of ghrelin or GH in these children. It has been reported that the levels of ghrelin can be modified by the increase in sex hormones [52]. In boys, a pharmacological administration of testosterone induced a marked decrease in ghrelin, whereas a pharmacological increase in estrogen had no effect on ghrelin levels in girls [53]. Of note, prepubertal girls have higher levels of estrogens and androgen metabolites compared with age-matched boys, and this higher prepubertal sex steroid levels in girls contribute to their earlier onset of puberty [54]. Moreover, Greenman, et al. [55] have shown that females have significantly higher ghrelin levels than males, both in the fasting state and after glucose and lipid loads. The effect of gender on ghrelin levels can be explained by higher levels in females of hormones involved in appetite regulation [56], and other hormones such as $\mathrm{GH}$ and prolactin [53]. Therfore, gender might be a possible reason for the discrepancy in our study and Al-Zaid, et al. [28] report. It might be also possible to assume that another reason for the variability in ghrelin levels could be due to technical problems [57].

Ghrelin, which is produced mainly in gastrointestinal tissues exerts multiple physiological functions. It stimulates appetite by acting on the hypothalamic arcuate nucleus, a region known to control food intake [29]. Under fasting conditions, ghrelin is secreted from the stomach and circulates in the bloodstream, thus transmits a hunger signal from the periphery to the central nervous system [30]. In addition, ghrelin plays an important role in synaptogenesis, mainly in the hippocampal area [30], and has a proliferative antiapoptotic effect in the central nervous system especially during oxygen/glucose deprivation [35]. Ghrelin is also an endogenous ligand of the $\mathrm{GH}$ secretagogue receptor (GHSR) and stimulates the release of GH [40]. This effect is guided largely by the expression of the ghrelin receptor GH secretagogue type 1a (GHS-R1a) in the hypothalamus and pituitary [40]. In animal model of induced GH deficiency, reduced ghrelin levels are influence by GH status [58]. These observations suggest a strong link between ghrelin and $\mathrm{GH}$, and in our results both of these hormones were found to be lower in children with autism compared with healthy children, 


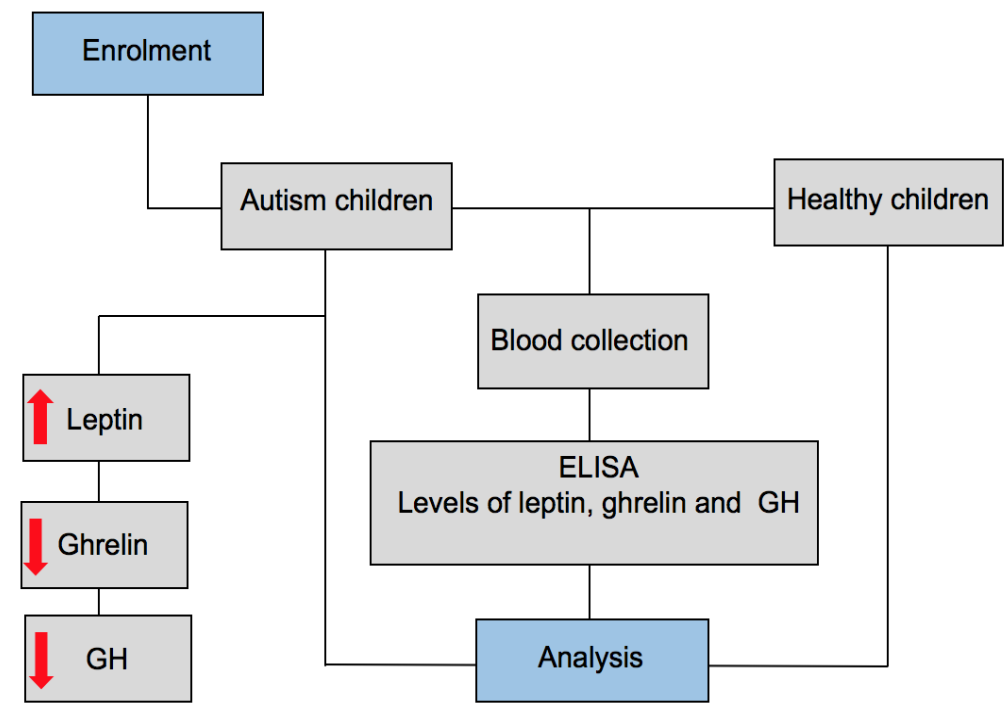

Figure 2: Schematic diagram of the main findings in this study. Serum levels of leptin, ghrelin, and growth hormone (GH) were measured by enzyme-linked immunosorbent assay (ELISA) in children with autism and age-matched healthy control children. The levels of leptin were higher and the levels of ghrelin, and $\mathrm{GH}$ were lower in children with autism compared with healthy controls.

although without reaching a statistical significance.

To the best of our knowledge, this is the first study in Bahrain that investigated the levels of leptin, ghrelin and GH in children with autism. A limitation in our study is the sample size, and further investigations in a larger sample size are needed to elucidate the implications of these hormones in autism.

The conclusion of our findings in this study is illustrated in Figure 2. Our data showed significantly higher serum levels of leptin in Bahraini children with autism compared with healthy children. While serum levels of ghrelin and $\mathrm{GH}$ appeared to be lower in autistic children than in healthy controls, both were not significantly different than in controls. This study is important to improve translation from medical research to health policy in Bahrain.

\section{Future Directions and Recommendations}

Further studies are required to clarify the relation of leptin, ghrelin and GH with the pathogenicity of autism. Indeed, studies in our lab are ongoing on larger samples not only to measure the levels of these hormones in autistic children but also to study them at the molecular level by conducting gene expression analysis. Moreover, genetic variation analysis are also important to explore the role of single nucleotide polymorphisms (SNPs) and other variants in autism pathogenesis.

\section{Acknowledgements}

We thank all participants at AlWafa centre (a subdivision of Bahrain Association of Intellectual Disability and Autism) and Aalia Early Intervention Centre in Bahrain for providing blood samples. We would like to thank the nurses at the laboratory of King Abdullah University Medical Centre (Arabian Gulf University,
Kingdom of Bahrain) and the technical staff at the Department of Molecular Medicine, College of Medicine and Medical Sciences, Arabian Gulf University.

\section{Conflict of Interest}

The authors have no conflict of interest, financial or otherwise.

\section{Funding}

This work was supported by a research grant (No: 37-PI-01/15) from the College of Medicine and Medical Sciences, Arabian Gulf University.

\section{References}

1. Levy SE, Mandell DS, Schultz RT (2009) Autism. Lancet 374: 1627-1638.

2. Lord C, Rutter M, Le Couteur A (1994) Autism diagnostic interview-revised: A revised version of a diagnostic interview for caregivers of individuals with possible pervasive developmental disorders. J Autism Dev Disord 24: 659-685.

3. Grace T Baranek, L Diane Parham, James W Bodfish (2013) Sensory and motor features in autism: Assessment and intervention. In: Fred $\mathrm{R}$ Volkmar, Rhea Paul, Ami Klin, Donald Cohen, Handbook of autism and pervasive developmental disorders. ( $3^{\text {rd }}$ edn), Wiley Online Library, 831-857.

4. Esposit G, Venuti P, Maestro S, Muratori F (2009) An exploration of symmetry in early autism spectrum disorders: Analysis of lying. Brain Dev 31: 131-138.

5. Ozonoff S, Young GS, Goldring S, Greiss-Hess L, Herrera AM, et al. (2008) Gross motor development, movement abnormalities, and early identification of autism. J Autism Dev Disord 38: 644-656.

6. Autism and Developmental Disabilities Monitoring Network Surveillance Year 2006 Principal Investigators, Centers for Disease Control and Prevention (CDC) (2009) Prevalence of autism spectrum disorders - Autism and developmental 
disabilities monitoring network, United States, 2006 MMWR Surveill Summ 58: 1-20.

7. Baxter AJ, Brugha TS, Erskine HE, Scheurer RW, Vos T, et al. (2015) The epidemiology and global burden of autism spectrum disorders. Physhol Med 45: 601-613.

8. Salhia HO, Al-Nasser LA, Taher LS, Al-Khathaami AM, ElMetwally AA (2014) Systemic review of the epidemiology of autism in Arab Gulf countries. Neurosciences (Riyadh) 19: 291-296.

9. Werling DM, Geschwind DH (2013) Sex differences in autism spectrum disorders. Curr Opin Neurol 26: 146-153.

10. Abrahams BS, Geschwind DH (2008) Advances in autism genetics: On the threshold of a new neurobiology. Nat Rev Genet 9: 341-355.

11. Gregory SG, Connelly JJ, Towers AJ, Johnson J, Biscocho D, et al. (2009) Genomic and epigenetic evidence for oxytocin receptor deficiency in autism. BMC Med 7: 62

12. Grabrucker AM (2012) Environmental factors in autism. Front Psychiatry 3: 118

13. Goyal DK, Miyan JA (2014) Neuro-immune abnormalities in autism and their relationship with the environment: A variable insult model for autism. Front Endocrinol (Lausanee) 5: 29.

14. Onorea C, Careagaa M, Ashwood P (2012) The role of immune dysfunction in the pathophysiology of autism. Brain Behav Immun 26: 383-392.

15. Kaluzna-Czaplinska J, Socha E, Rynkowski J (2010) Determination of homovanillic acid and vanillylmandelic acid in urine of autistic children by gas chromatography/ mass spectrometry. Med Sci Monit 16: CR445-450.

16. Anderson GM, Hertzig ME, McBride PA (2012) Brief report: Platelet-poor plasma serotonin in autism. J Autism Dev Disord 42: 1510-1514.

17. Hammock E, Veenstra-VanderWeele J, Yan Z, Kerr TM, Morris M, et al. (2012) Examining autism spectrum disorders by biomarkers: Example from the oxytocin and serotonin systems. J Am Acad Child Adolesc Psychiatry 51: 712-721.

18. Chen MH, Su TP, Chen YS, Hsu JW, Huang KL, et al. (2013) Comorbidity of allergic and autoimmune diseases in patients with autism spectrum disorder: A nationwide population-based study. Research in Autism Spectrum Disorders 7: 205-212.

19. Mrozek-Budzyn D, Majewska R, Kielyka A, Augustyniak $M$ (2013) The frequency and risk factors of allergy and asthma in children with autism--case-control study. Przegl Epidemiol 67: 675-679, 761-674.

20. Lin TY, Lin PY, Su TP, Chen YS, Hsu JW, et al. (2014) Autistic spectrum disorder, attention deficit hyperactivity disorder, and allergy: Is there a link? A nationwide study. Research in Autism Spectrum Disorders 8: 1333-1338.

21. Wasilewska J, Klukowski M (2015) Gastrointestinal symptoms and autism spectrum disorder: Links and risks - a possible new overlap syndrome. Pediatric Health Med Ther 6: 153-166.

22. Chaidez V, Hansen RL, Hertz-Picciotto I (2014) Gastrointestinal problems in children with autism, developmental delays or typical development. J Autism Dev Disord 44: 1117-1127.

23. Tareen RS, Kamboj MK (2012) Role of endocrine factors in autistic spectrum disorders. Pediatr Clin North Am 59: $75-88$.
24. Ashwood P, Kwong C, Hansen R, Hertz-Picciotto I, Croen L, et al. (2008) Brief report: Plasma leptin levels are elevated in autism: Association with early onset phenotype? J Autism Dev Disord 38: 169-175.

25. Klok MD, Jakobsdottir S, Drent ML (2007) The role of leptin and ghrelin in the regulation of food intake and body weight in humans: A review. Obes Rev 8: 21-34.

26. Meister B (2000) Control of food intake via leptin receptors in the hypothalamus. Vitam Horm 59: 265-304.

27. Ahima RS, Osei SY (2004) Leptin signaling. Physiol Behav 81: 223-241.

28. Al-Zaid FS, Alhader AA, Al-Ayadhi LY (2014) Altered ghrelin levels in boys with autism: A novel finding associated with hormonal dysregulation. Sci Rep 4: 6478.

29. Kojima M, Kangawa K (2005) Ghrelin: structure and function. Physiol Rev 85: 495-522.

30. Diano S, Farr SA, Benoit SC, McNay EC, da Silva I, et al. (2006) Ghrelin controls hippocampal spine synapse density and memory performance. Nat Neurosci 9: 381-388.

31. Bourgeron T (2015) From the genetic architecture to synaptic plasticity in autism spectrum disorder. Nat Rev Neurosci 16: 551-563.

32. Carpita B, Muti D, Dell'Osso L (2018) Oxidative stress, maternal diabetes, and autism spectrum disorders. Oxid Med Cell Longev 2018: 3717215.

33. Marchio M, Roli L, Giordano C, Caramaschi E, Guerra A (2018) High plasma levels of ghrelin and des-acyl ghrelin in responders to antiepileptic drugs. Neurology 91: e62-e66.

34. Besag FMC (2018) Epilepsy in patients with autism: Links, risks and treatment challenges. Neuropsychiatr Dis Treat 14: $1-10$.

35. Zhao Z, Sakata I, Okubo Y, Koike K, Kangawa K, et al. (2008) Gastric leptin, but not estrogen and somatostatin, contributes to the elevation of ghrelin mRNA expression level in fasted rats. J Endocrinol 196: 529-538.

36. Matsuda K, Nishi Y, Okamatsu Y, Kojima M, Matsuishi T (2006) Ghrelin and leptin: A link between obesity and allergy? J Allergy Clin Immunol 117: 705-706.

37. Guler N, Kirerleri E, Ones U, Tamay Z, Salmayenli N, et al. (2004) Leptin: Does it have any role in childhood asthma? J Allergy Clin Immunol 114: 254-259.

38. Dixit VD, Schaffer EM, Pyle RS, Collins GD, Sakthivel SK, et al. (2004) Ghrelin inhibits leptin- and activation induced proinflammatory cytokine expression by human monocytes and T cells. J Clin Invest 114: 57-66.

39. Gorschl M, Wagner R, Dotsch J, Rascher W, Rauh M (2002) Preanalytical influences on the measurement of ghrelin. Clin Chem 48: 1114-1116.

40. Saleri R, Giustina A, Tamanini C, Valle D, Burattin A, et al. (2004) Leptin stimulates growth hormone secretion via a direct pituitary effect combined with a decreased somatostatin tone in a median eminence-pituitary perifusion study. Neuroendocrinology 79: 221-228.

41. Sun $Y$, Wang $P$, Zheng $H$, Smith RG (2004) Ghrelin stimulation of growth hormone release and appetite is mediated through the growth hormone secretagogue receptor. Proc Natl Acad Sci USA 101: 4679-4684.

42. (2013) Diagnostic and Statistical Manual of Mental Disorders (DSM-5). ( $5^{\text {th }}$ edn), American Psychiatric Association, Washington, DC.. 
43. Ozonoff S, Goodlin-Jones BL, Solomon M (2005) Evidencebased assessment of autism spectrum disorder in children and adolescents. J Clin Child Adolesc Psychol 34: 523-540.

44. Tworoger SS, Hankinson SE (2006) Collection, processing, and storage of biological samples in epidemiologic studies: Sexhormones, carotenoids, inflammatory markers, and proteomics as examples. Cancer Epidemiol Biomarkers Prev 15: 1578-1581.

45. Shanley LJ, Irving AJ, Harvey J (2001) Leptin enhances NMDA receptor function and modulates hippocampal synaptic plasticity. J Neurosci 21: 186.

46. Fantuzzi G, Faggioni $R$ (2008) Leptin in the regulation of immunity, inflammation, and hematopoiesis. J Leukoc Biol 68: 437-446.

47. Ahima RS, Saper CB, Flier JS, Elmquist JK (2000) Leptin regulation of neuroendocrine systems. Front Neuroendocrinol 21: 263-307.

48. Blardi P, de Lalla A, Ceccatelli L, Vanessa G, Auteri A, et al. (2010) Variations of plasma leptin and adiponectin levels in autistic patients. Neurosci Lett 479: 54-57.

49. Bellone S, Prodam F, Savastio S, De Rienzo F, Demarchi I, et al. (2012) Acylated and unacylated ghrelin levels in normal weight and obese children: Influence of puberty and relationship with insulin, leptin and adiponectin levels. J Endocrinol Invest 35: 191-197.

50. Falorni A, Bini V, Molinari D, Papi F, Di Stefano G, et al. (1997) Leptin serum levels in normal weight and obese children and adolescents: Relationship with age, sex, pubertal development, body mass index and insulin. Int $J$ Obes Relat Metab Disord 10: 881-890.
51. Rodrigues DH, Rocha NP, Sousa LF, Barbosa IG, Kummer A, et al. (2014) Changes in adipokine levels in autism spectrum disorder. Neuropsychobiology 69: 6-10.

52. Lebenthal Y, Gat-Yablonski G, Shtaif B, Padoa A, Phillip $M$, et al. (2006) Effect of sex hormone administration on circulating ghrelin levels in peripubertal children. J Clin Endocrinol Metab 91: 328-331.

53. Maccario M, Aimaretti G, Corneli G, Gauna C, Grottoli S, et al. (2000) Short-term fasting abolishes the sex-related difference in $\mathrm{GH}$ and leptin secretion in humans. Am J Physiol Endocrinol Metab 279: E411-E416.

54. Courant F, Aksglaede L, Antignac JP, Monteau F, Sorensen K, et al. (2009) Assessment of circulating sex steroid levels in prepubertal and pubertal boys and girls by a novel ultrasensitive gas chromatography-tandem mass spectrometry method. J Clin Endocrinol Metab 95: 82-92.

55. Greenman Y, Golani N, Gilad S, Yaron M, Limor R, et al. (2004) Ghrelin secretion is modulated in a nutrient- and gender-specific manner. Clinical Endocrinol 60: 382-388.

56. Casabiell X, Pineiro V, Vega F, De La Cruz LF, Dieguez C, et al. (2001) Leptin, reproduction and sex steroids. Pituitary 4: 93-99.

57. Blatnik M, Soderstrom Cl (2011) A practical guide for the stabilization of acylghrelin in human blood collections. Clin Endocrinol (Oxf) 74: 325-331.

58. Caminos JE, Seoane LM, Tovar SA, Casanueva FF, Dieguez C (2002) Influence of thyroid status and growth hormone deficiency on ghrelin. Eur J Endocrinol 147: 159163. 